REVISTA DE ESTUDOS EM ARTES CÊNICAS

E-ISSN 2358.6958

\title{
Caminhos interativos em Viewpoints: Apontamentos e inflexões em "Sete tons de uma poesia"
}

Iara Cerqueira Linhares de Albuquerque

\section{Para citar este artigo:}

ALBUQUERQUE, lara Cerqueira Linhares de. Caminhos interativos em Viewpoints: Apontamentos e inflexões em "Sete tons de uma poesia". Urdimento - Revista de Estudos em Artes Cênicas, Florianópolis, v. 3, n. 42, dez. 2021.

do) DOI: http:/dx.doi.org/10.5965/1414573103422021e0104

Este artigo passou pelo Plagiarism Detection Software| iThenticate 
Caminhos interativos em Viewpoints: Apontamentos e inflexões em "Sete tons de uma poesia"1

lara Cerqueira Linhares de Albuquerque ${ }^{2}$

\begin{abstract}
Resumo
Esse artigo descreve um processo de criação em dança, partindo de estudos teóricos/prático, sob o viés co-evolutivo de entendimento de corpo como mídia de si mesmo, amparada pela Teoria Corpomídia, pelo método desenvolvido pela diretora norte-americana Anne Bogart, o Viewpoints e a partir da experiência em sala de aula com jovens moradores do bairro Alto de Santa Cruz. Esses jovens marcados por violência e mortes diárias e a realidade precária do professor de escola pública, são referências à montagem da obra Sete Tons de uma Poesia. A escrita apresenta inferências pessoais como artista e docente na Rede Municipal de Salvador, que entende ambos como ação política, cujo foco se encontra em questões singulares e locais.
\end{abstract}

Palavras-chave: Viewpoints. Dança. Educação. Professor. Teoria Corpomídia.

\title{
Interactive Paths in Viewpoints: Notes and Inflections in "Seven Tones of Poetry"
}

\begin{abstract}
This article, describe a process of creation in dance, based on theoretical/practical studies, under the co-evolutionary bias of understanding the body as a media of itself, supported by the Teoria Corpomídia, by the method developed by the North American director Anne Bogart, the Viewpoints are based on the classroom experience with young residents of the Alto de Santa Cruz neighborhood. These young people, marked by violence and daily deaths, and the precarious reality of the public school teacher, are references to the assembly of the work Seven Tons of a Poetry. This writing, present personal inferences as an artist and teacher in the Municipal Network of Salvador, which understands both as political action, whose focus is on singular and local issues.
\end{abstract}

Keywords: Viewpoints. Dance. Education. Teacher. Teoria Corpomídia.

${ }^{1}$ Revisão ortográfica e gramatical do artigo realizada por Eduardo Reis. Doutorando em Artes Cênicas pela UFBA. Mestrado em Literatura e Crítica Literária pela (PUC/SP - 2019). Licenciatura Plena em Filosofia pela Faculdade do Mosteiro de São Bento. Professor universitário.

2 Doutorado em Comunicação e Semiótica (PUC - SP (2016). Professora adjunta do Departamento de Ciências Humanas e Letras no curso de Licenciatura em Dança da Universidade Estadual do Sudoeste da Bahia (UESB). Colaboradora no Programa de Pós-Graduação em Letras: Cultura, Educação e Linguagem - PPGCELUESB. iara.linhares@uesb.edu.br 
Caminos interactivos en puntos de vista: notas e inflexiones en "Siete tonos de poesía"

\section{Resumen}

Este artículo describe un proceso de creación en danza, basado en estudios teóricoprácticos, bajo la perspectiva coevolutiva de entender el cuerpo como un medio de sí mismo, apoyado en la Teoría Corpomídia, mediante el método desarrollado por la directora norteamericana Anne Bogart, o Miradores y desde el aula con jóvenes vecinos del barrio Alto de Santa Cruz. Estos jóvenes, marcados por la violencia y las muertes cotidianas, y la precaria realidad del maestro de escuela pública, son también referencias al montaje de la obra Sete Tons de uma Poesia. El escrito presenta inferencias personales como artista y docente en la Red Municipal de Salvador, que entiende a ambos como acción política, cuyo enfoque está en temas singulares y locales.

Palabras clave: Miradores. Danza. Educación. Maestro. Teoría Corpomídia. 
Descaminhos poéticos: ou como gerar redes e aproximações em Viewpoints

O primeiro contato com o Viewpoints aconteceu com Donnie Mather ${ }^{3}$ (EUA) no II ENGRUPE DANÇA (2009) no Rio de Janeiro, a partir de um lugar de curiosidade e desconhecimento sobre esse método e com a vontade de aprender uma prática física que envolvesse ações de improvisação no espaço compartilhado ao mesmo tempo com autonomia e escuta. Fizemos alguns exercícios iniciais e logo no primeiro momento de experimentação, estudamos aspectos e princípios referentes ao Viewpoints que envolve dentre outras coisas, atenção, concentração e escuta. Percebemos como se fazem necessárias ativações cognitivas para execução dessa proposta. Esse primeiro encontro me fez refletir sobre quais possibilidades e ações são urgentes e pontuais para serem utilizadas durante uma prática de improvisação. Observei nessa experiência inicial que incluía caminhar em raia, associar atividade física, artística e cognitiva de ouvir/sentir, ou de escuta/sensação que se intensifica e avança à medida que adentramos a uma negociação dialógica contínua, a partir de um determinado tempo dado de execução.

Aquele meu primeiro momento era puro deleite a uma possibilidade de composição que, além de estar em coletivo, permitia que ação e emoção estivessem juntas, nos músculos, coração e pulmões. Contudo, nas instruções de Donnie Mather pudemos compreender que as possibilidades de gerar ações em grupo precisavam estar baseadas na relação com os corpos no que tange às noções de tempo e espaço. A ideia de protagonismo e intenções prévias por um viés individual e subjetivo não fazem parte da proposta e nesse sentido, pensar a prática do Viewpoints desde essa primeira experiência até os tempos atuais se torna muito importante, nesse momento que nos encontramos. Ainda sobre essa experiência na sala de aula com Donnier e os colegas, pude perceber a possibilidade de um exercício ético, colaborativo e investigativo que poderia ser desenvolvido em qualquer processo artístico ou nas aulas de dança.

Os Six Viewpoints (espaço, história, tempo, emoção, movimento e forma),

${ }^{3}$ Ator, Professor e praticante do Viewpoints. 
sistematizados por Mary Overlie, tem no corpo seu foco que está em constante negociação e disposições espaço/tempo, uma vez que nesse processo vivo, aquisições de conhecimentos se modificam continuamente e acionamentos se fazem urgentes quando se trabalha com referências e estímulos variados. É necessário acordar todo o corpo, ter como foco o ambiente e seu entorno, além dos aspectos correlacionais do grupo ou coletivo em ação, um encontro que pode ser entendido em processos de percepção, cognição e ação em que um determinado corpo pode realizar (Wachowicz, 2016).

De partida, pude refletir sobre a real necessidade de nos mantermos ativos, atentos e em escuta durante toda essa prática, quer seja andando, pulando, correndo, caindo e recuperando-se. Mary Overlie foi influenciada pelas propostas experimentais de um grupo de artistas do qual fazia parte, a Judson Church Theater na década de 60. Se formos atualizar rápido e historicamente sobre esses artistas podemos entender que o Viewpoints contém aspectos desse entendimento corporal, quando eles buscavam desenvolver na execução prática resposta aos estímulos externos, com atenção e consciência a partir da conexão com os outros, com responsabilidade e dinâmicas grupais, a partir das conexões geradas nesse trânsito (Belém, 2017).

Retorno à memória os artistas da Judson Church Theater para discorrer mais sobre minhas expectativas, que dentre outras coisas, assim como eles buscava possibilidades de compor jogos, gerar autoconhecimento e também motivação ao aprendizado formal, já que eu trabalhava numa escola do município com crianças da periferia de Salvador. A proposta foi trabalhar com aulas de dança no turno oposto às atividades regulares desenvolvidas nos componentes curriculares.

Como artista/docente, busquei trazer referências desse grupo para o ambiente escolar e na continuação espelhar essa prática de improvisação na composição de um processo de criação artística. Em Sete Tons de uma poesia propus tecer artisticamente com os alunos de 8 a 12 anos de turmas diversas da escola Artur de Sales, no Alto de Santa Cruz, situada em Salvador, Bahia. O título que escolhi para montagem desta obra de dança aconteceu de forma inesperada durante o intervalo das aulas. Estava sentada na biblioteca e me deparei com o livro do professor e escritor baiano Cláudio Veiga, que tinha como título Sete Tons de uma poesia maior- 
Uma leitura de Artur de Sales (2002). Tratava-se de uma série de poesias de Artur de Sales, escritor pouco conhecido e nome da primeira escola do município em que trabalhei. Como o título me encantou, decidi fazer essa homenagem ao poeta.

Retornei a sala de aula e ao contato com os alunos buscando outras possibilidades de olhar aqueles corpos em coletivo, naquele pequeno espaço quando tínhamos (às vezes as aulas aconteciam no corredor, na copa, e na quadra, disputando com os professores de educação física e música). Observei que a atenção exercitada, a escuta e o foco, elementos utilizados no Viewpoints seria uma proposta efetiva de (r) existência naquele ambiente com as crianças vítimas diárias de abuso, violência, marcadas por maus tratos, abandono e fome.

A ideia naquele momento estava também em criar possibilidades aos alunos para que eles pudessem vir a dançar, sonho de muitos estudantes da escola e buscar nas referências corporais dos alunos, informações para montagem de Sete Tons. No decorrer do período que atuei como professora da rede recorri ao Viewpoints aliado a minha experiência pessoal como artista e professora de dança, além de jogos, brincadeiras infantis e aulas introdutórias de dança e balé clássico.

Meu interesse como essa prática se intensificou gerando expectativas, vislumbrando inclusive ampliar a consciência dos hábitos cognitivos para aprendizagem dentro da sala de aula, pois o fator criatividade pode vir a criar estímulos cognitivos a partir de ações pontuais do/no corpo, que segundo Katz (2010, p.122) "funciona como uma referência propícia, através da experiência de reencantamento que brota do desafio de desvendá-lo”, assim, para agir preciso "olhar o outro" perceber o outro e escutar o outro,

\footnotetext{
Neste sentido, os Viewpoints como prática teatral na disciplina de Artes na escola se configuraram como um caminho para o olhar sobre a relação com o espaço que os envolve, com o próprio corpo, o corpo do outro, a relação destes corpos no mesmo espaço, a consciência do trabalho em grupo, ajuda mútua, cooperação e a influência deste trabalho no convívio cotidiano (Lodi, 2009, p.3).
}

Pensar o espaço pessoal foi outra característica apresentada por Donnie durante sua aula, além de mais algumas observações, que após a leitura dos textos de Sandra Meyer e Fabiano Lodi, professores e pesquisadores do método me 
ajudaram a conhecer e praticar o Viewpoints. Na sala de aula pude reconhecer a enorme proporção que o Viewpoints pode vir a ajudar nos processos pessoais de reconhecimento de si, a encontrar caminhos e pontos de fuga, inclusive se posicionando politicamente. Dentre esses caminhos, podemos citar a importância da atenção durante a prática em Viewpoints a partir da concentração que amplia a mobilização do corpo de forma consciente e como esse estado de prontidão se torna também foco de um interesse pessoal. Na prática coletiva pude sentir que eles se mantinham atentos enquanto estado de corpo, fazendo que percebêssemos a importância da sintonia com o outro e consigo mesmo. De forma geral, o trajeto que íamos percorrendo trazia um pouco de nós, já contaminados com tudo que estava presente e captado pelos órgãos sensoriais em tempo real, tendo atenção ao que íamos respondendo enquanto movimento, sempre em relação ao coletivo, espaço e situações.

A liberdade nesse processo aparentemente solta, se encontra atrelada às relações em fluxo e foram se constituindo durante todo o processo de ensino/aprendizagem, nos encontros das aulas, nas conversas após as práticas sobre cada atividade proposta e durante os ensaios para montagem com a participação efetiva de todos. Aproveito para sinalizar que não me interessa demarcar um lugar entre ser professora ou artista, mas artista/docente, docente/artista, um posicionamento político que defendo desde a minha graduação no curso de Licenciatura em Dança na UFBA. Inclusive porque proponho escrever exatamente assim nesse artigo.

Durante os depoimentos dos alunos pude constatar que as várias repetições, durante a aplicação do Viewpoints não se tornaram enfadonhas e repetitivas como nas aulas de balé, ao contrário, se tornavam crescentes e à medida que a improvisação estava sendo feita, reorganizava-se todo o grupo, o espaço com os materiais utilizados, como bolas, sacos de lixo e máscaras que sempre e confortavelmente tomavam conta da sala/cena.

Apesar de algumas pessoas serem contra o ensino de balé clássico na rede municipal, a ideia de ensinar balé clássico de maneira introdutória fazia parte dos sonhos da maioria dos alunos e continuar a não aproximá-lo da periferia me soava um tanto elitista. Porém reconheço a importância do ensino de outras danças 
inclusive populares nesses espaços. Nunca elaborei planos para as aulas, mas roteiros que constavam das práticas corporais como preparação inicial, durante o decorrer da aula aplicava jogos em grupo, fazíamos estudo do espaço da sala com as cadeiras e para finalizar, fazíamos leitura de histórias infantis ou sobre história da arte. Buscava junto à coordenação atividades complementares como: visitas ao teatro e exposições temáticas mensalmente.

Nas aulas/ensaios do Viewpoints a sensação de quem assiste é de que a performance apresentada foi anteriormente ensaiada, porém a conexão que se instaura são frutos desses acionamentos neuromotores, como cita Alva Nóe (2012). Ainda segundo Nóe (2012), isso ocorre a partir das habilidades cognitivas e conhecimentos do nosso corpo e com isso, amplia aspectos da consciência. Numa perspectiva semiótica, esse processo relacional instaura-se a partir de pontos de conexão ou algum tipo de similaridade entre as propriedades dos termos relacionados, que podem variar, como a mais esdrúxula fantasia concebida da realidade percebida (Britto, 2008) que opera em fluxo contínuo corpomente, sem a separação de movimento e pensamento (Katz \& Greiner, 2005).

Diante disso, essa prática nos ajuda a perceber outros processos corporais e sua possibilidade de poder ser estudada por todos os corpos, sem dicotomias, onde o pensamento é entendido como o jeito que o movimento encontrou para se organizar, se apresentar e resultar numa bela performance.

Durante os exercícios de Viewpoints observei que aspectos informais como exercitar a escuta, o caminhar juntos, companhias na execução de alguns movimentos similares, por exemplo, alguns até fazem parte de nosso dia a dia, não eram muito fáceis para aqueles alunos. Esse aspecto informal de estar em coletivo se torna em alguns momentos condição para essa prática, que se codetermina mutuamente e tem no corpo que movimenta encontros, momentos e parcerias.

Roteiros criativos e andanças: Parcerias de corpos, com corpos e em corpos

Na dança, o corpo faz acordos, roteiros e cria conexões como condição de 
sobrevivência e continuidade. Tais conexões ocorrem em rede pela sua natureza complexa numa retroalimentação corpo/ ambiente que como já fora citado antes, se contaminam mutuamente. Esta contaminação é característica dos processos co-evolutivos e não elimina a especificidade dos contextos levantados, são sistemas de linguagem que dialogam numa ação interativa. Essa ação de criação artística que proponho apresentar se organiza como uma ação cognitiva do corpo, na contramão de um pensamento que prescinde de autoexplicações, assim, entende-se que um processo que envolve a criação de uma obra qualquer que seja ela, não para de promover traduções significativas. Como a literatura, escultura, pintura, dentre outras, uma obra de dança é repleta de imagens e pensamentos, signos formalizados em dança.

Criações em dança parecem se constituir de escrituras sígnicas e de certa forma políticas, por serem frutos de imagens produzidas no/pelo corpo e ambiente. E assim se organiza Sete Tons de uma poesia, além de uma prática crítica e reflexiva, tem como principais referências minhas experiências como professora nas aulas e no dia-a-dia naquele espaço, com tiros, relatos de violência, mortes e assaltos.

Não sem motivos, há uma necessidade, cada vez mais urgente, de uma
pluralidade de projetos coletivos articulados de modo não hierárquico e
que estejam atentos aos processos de tradução que vão substituir a
formulação de uma teoria geral para uma teoria cada vez mais específica
e localizada. Não se trata de propor o fim das utopias, mas sim, de
reconhecer utopias plurais e críticas ou, como propôs Foucault (1966), a
utopia como um lugar fora de todos os lugares (Greiner, 2010, p.25).

O Viewpoints ao ser definido por Bogart e Landau (2017) como um processo aberto e não rigidamente formatado (Meyer, 2008), nos possibilita olhar o corpo em fluxo de atravessamentos não estanques e com alta complexidade organizativa. Propor qualquer atividade numa sala sem piso próprio, sem espaço para locomoção, sem contar com som e material necessário foi muito desafiante, pela extrema dispersão desse público de alunos de 8 a 12 anos do ensino fundamental.

Em sua proposta de percepção espaço-tempo o Viewpoints possibilita autonomia entre as partes no qual o corpo apreende, seleciona, organiza e transforma as informações que the chegam do ambiente, como mídia de si mesmo 
em trocas constantes com o ambiente, propulsor de várias e contínuas informações. Isso pode ser visto nas imagens filmadas após as aulas e presentes na cena, ressaltando inclusive a disponibilidade de fazer as atividades propostas em coletivo. Senti-me contemplada ao perceber o quanto essa prática dialoga com a filosofia da partilha do sensível, de Jacques Rancière (2005) que consiste nas maneiras de fazer de um conjunto comum partilhado.

Segundo Rancière (2005), as práticas artísticas são "maneiras de fazer", nas relações e maneiras de ser, de se posicionar e habitar o espaço que ocupam. Um exemplo prático ocorreu quando trabalhávamos com um dos exercícios de Viewpoints em que todos caminham pelo espaço e quando alguém para, todos param. As formas de partilha do sensível podem ser percebidas nas reações ocorridas nos ensaios. De maneira geral para aquelas crianças tudo era motivo de riso e esse exercício de perceber e parar sem olhar diretamente o outro provocava de maneira coletiva uma receptividade engraçada, sensível e de abertura para uma boa risada em comum, gerando momentos de descontração. Cada corpo reagiu de um jeito numa pluralidade de risos os tornando voz de uma reação e/ou ação e uma relação entre o fazer, o ser e o dizer.

Incentivar a percepção dos movimentos do outro, no agir, no deslocar e no parar, provocou em alguns momentos tensão, em outros momentos atenção e em outros, estado de prontidão, tudo isso ocorria sob minha orientação. Observei que ações ocorridas inicialmente de maneiras distintas geram sentidos, do mesmo modo como os acontecimentos contados pelos estudantes sobre suas vidas no início das aulas, reverberaram nos nossos corpos criando imagens em movimento e assim temos a arte na sua prática que legitima o lugar de uma ação política e engajada. Ou como afirma Rancière (2005) em relação às práticas artísticas a partir de sua filosofia, como uma constituição de mundo sensível comum, entrelaçados numa pluralidade de reações humanas e suas singularidades.

As práticas artísticas são "maneiras de fazer" que intervém na distribuição geral das maneiras de fazer e nas suas relações com maneiras de ser e formas de visibilidade. [...], quaisquer que sejam as intenções que as regem, os tipos de inserção social dos artistas ou o modo como às formas artísticas refletem estruturas ou movimentos sociais (Rancière, 2005, p.1718). 
Enquanto professora com o olhar ativo e afinado, mesmo nas caminhadas, percebi a importância da evolução de cada um junto com eles, e mesmo na simplicidade da proposta, se observa uma conduta extremamente complexa para o trabalho em grupo (Meyer. 2008), principalmente com os alunos dessa escola.

Para participar das aulas/ensaios convidei Victor Venas, professor e artista visual para fazer a direção do projeto artístico, que de imediato topou e hoje percebo a importância desse encontro durante o percurso criativo e as sugestões geradas na produção do vídeo a partir dos exercícios investigativos com o Viewpoints. Na mostra da obra Sete tons de uma poesia ao público, além de citar os corpos dos estudantes via imagens em vídeo, como mídia de si mesma, a proposta foi apresentar questões pessoais e tensões sobre minha atuação na rede municipal de ensino para criação das cenas. Victor Venas fez uma excelente contribuição, tanto na tessitura das cenas, na cenografia, na orientação da escolha do figurino e na captura das imagens utilizadas, quanto pela sugestão de usarmos o discurso de uma professora de Natal como sonorização, pois segundo ele, haviam questões comuns, referentes a nossa realidade como professora.

Figura 1 - Sete Tons de uma Poesia. Direção, videografia: Victor Venas. Concepção e performance: Iara Cerqueira. Fotografia: João Meirelles

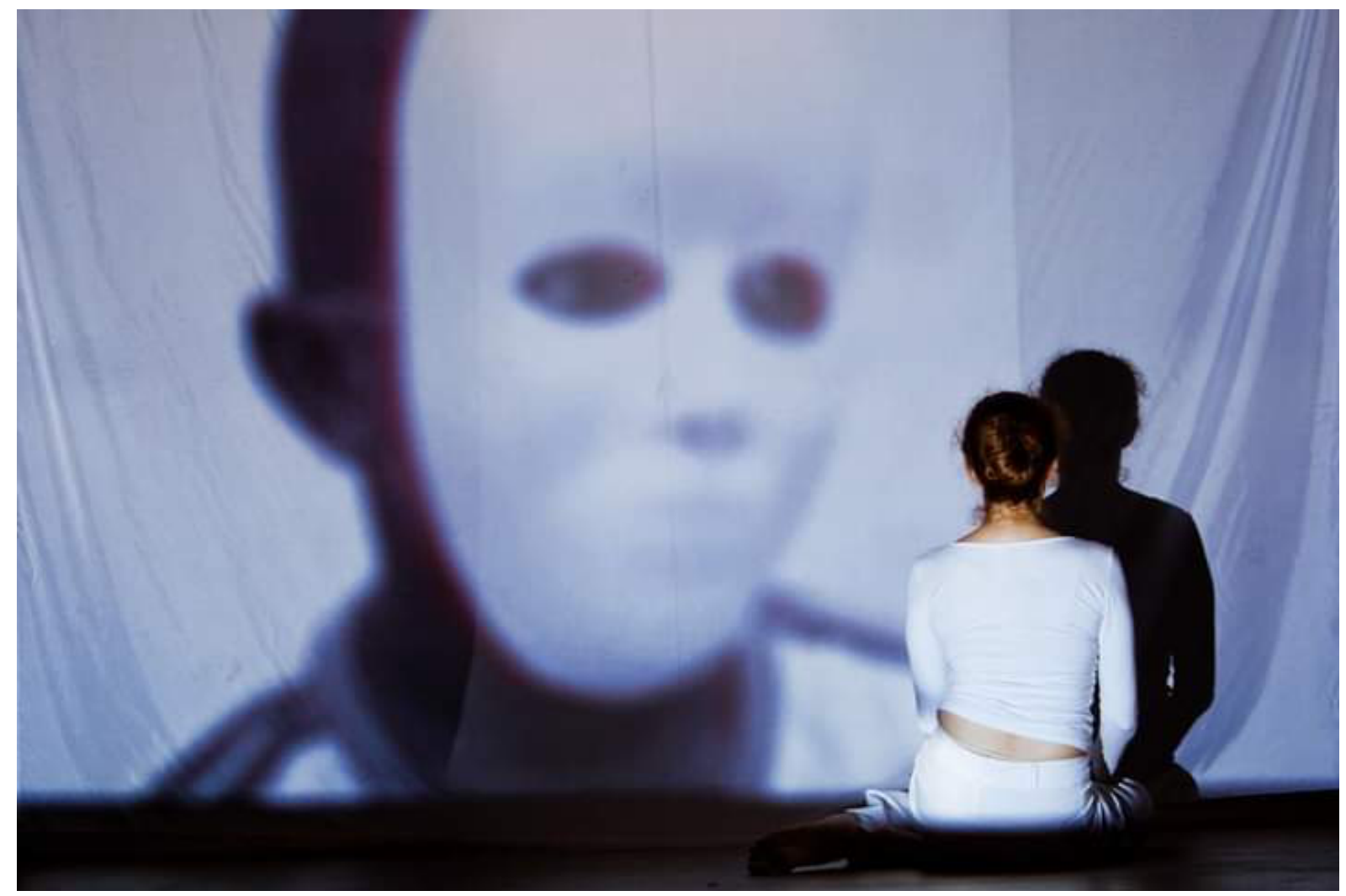


A cenografia foi composta de um pano branco onde eram projetadas as imagens dos alunos e uma corda no qual me pendurei, trazendo a metáfora de estar de fato, vivendo eu e os alunos por um fio naquela comunidade. Sobre o figurino que usei optamos por algo confortável e solto como calça e blusa brancas, já que as imagens iriam ser projetadas também em meu corpo. O figurino dos alunos foi a farda da escola. Na sonorização, usamos minha voz e o discurso proferido pela professora Amanda Gurgel (RN), que ficou conhecida após fazer um pronunciamento na Assembleia Legislativa do Rio Grande do Norte a respeito da situação da educação no estado, resultando num vídeo acessado por mais de um milhão de internautas no YouTube ${ }^{4}$, porém naquele momento já havia caído no esquecimento.

A escolha desse discurso proferido pela professora como inspiração e sonorização dessa proposta, se situa também como uma ação micropolítica (Rolnik, 2018) de continuar a discussão implantada pela professora em relação ao ensino, porém aproximando à realidade da rede pública municipal de Salvador. Acho interessante aproximar essa ação artística à definição de micropolítica apresentada por Sueli Rolnik (2018), mesmo que brevemente, por entender que se configura com tal. Apesar de sua obra Esferas da Insurreição: Notas para uma vida não cafetinada não ser direcionada à área de educação, essa proposta se articula como uma ação micropolítica de uma artista/docente de Salvador.

A autora sugere que desatemos os nós de afetos que produzem em nossa garganta e apresenta como proposta pulsante de uma micropolítica ativa, agir em favor da vida como força de criação (Rolnik, 2018). Vejo-me implicada politicamente nessa ação como artista/docente e principalmente na materialização da cena do grito cala a boca para a plateia. Segundo Rolnik (2018), a esfera micropolítica está pautada na existência humana que se fazem atreladas aos afetos e habitá-la é essencial para nos situarmos e fazermos escolhas, nos resguardar e potencializar nossas vidas. Nesse artigo, apresento o Viewpoints também como possibilidade para repensarmos os modelos tradicionais de educação, assim como as práticas artísticas em dança contemporânea.

${ }^{4}$ Link disponível: https://www.youtube.com/watch?v=hAssVIVNdTw Acesso em: 28 ago. 21. 
Voltando a escolha do discurso como sonorização de nossa obra, relato que a reação inicial proferida pelo discurso da professora foi bastante comentada nas redes sociais e jornais da época e desde então, ninguém mais ouve falar, característica da nossa sociedade contemporânea. Nas conversas com professoras de outras escolas, percebi que as questões apresentadas pela professora Amanda parecem criar ecos com os profissionais de dança nas escolas de periferia de Salvador. Nesse sentido pensar o corpo que dança e descrever ações e feituras em movimento, poesia e prosa, representa o sentido sistêmico em que se insere dança no seu fazer artístico, comunicacional e como produtora de novos signos. Katz (2010, p.121), cita: “O corpo em movimento é a matriz da comunicação e da cognição. Com o movimento, a ação do corpo, vai corporificando as trocas incessantes com os ambientes" e afirma pontos importantes no campo da dança, no que diz respeito a um processo de criação em dança e suas intersecções, assim como possibilidades de se pensar outros modos de fazer dança e possíveis quebras de habitualidades de movimento. Sandra Meyer (2008, p.2), nos contempla quando cita,

Os Viewpoints e o trabalho sobre a composição oscilam entre o movimento e a pausa, entre o desejo pela variedade de ações e a economia do movimento. Ora limitando o corpo a ações mínimas, ora incitando a profusão e diversidade de formas, o método permite ao ator a oportunidade de trabalhar sua percepção e ação com atenção ao momento presente, aguçando sua sensibilidade em sintonia com o outro e com o ambiente em que se insere.

Como ressalta Sandra Meyer, essa proposta sai do automatismo e pode vir a gerar modos diferentes de ensinar/dançar e criar relações com o outro, inclusive de sintonia. Ressalto o exercício político dessa prática como propulsora de questões pessoais e profissionais, o que difere de um produtor de arte mecanizada, direcionada a uma demanda de mercado, ou de práticas temáticas como pensa a maioria dos coordenadores de escola sobre a disciplina de artes.

Preciso deixar registrado, uma lembrança que me ocorreu nesse momento de escrita e que acho necessário trazer ao texto agora. Durante a apresentação de Sete Tons de Uma Poesia, no Teatro Xisto Bahia e no Teatro Plataforma em Salvador, Bahia, questões importantes se instauram também nos corpos que assistiam nossa apresentação em função do meu grito de cala a boca, junto ao discurso da 
professora Amanda Gurgel $(R N)$ e às imagens das crianças na tela. No final das apresentações a pergunta de sempre: Para quem é esse grito?
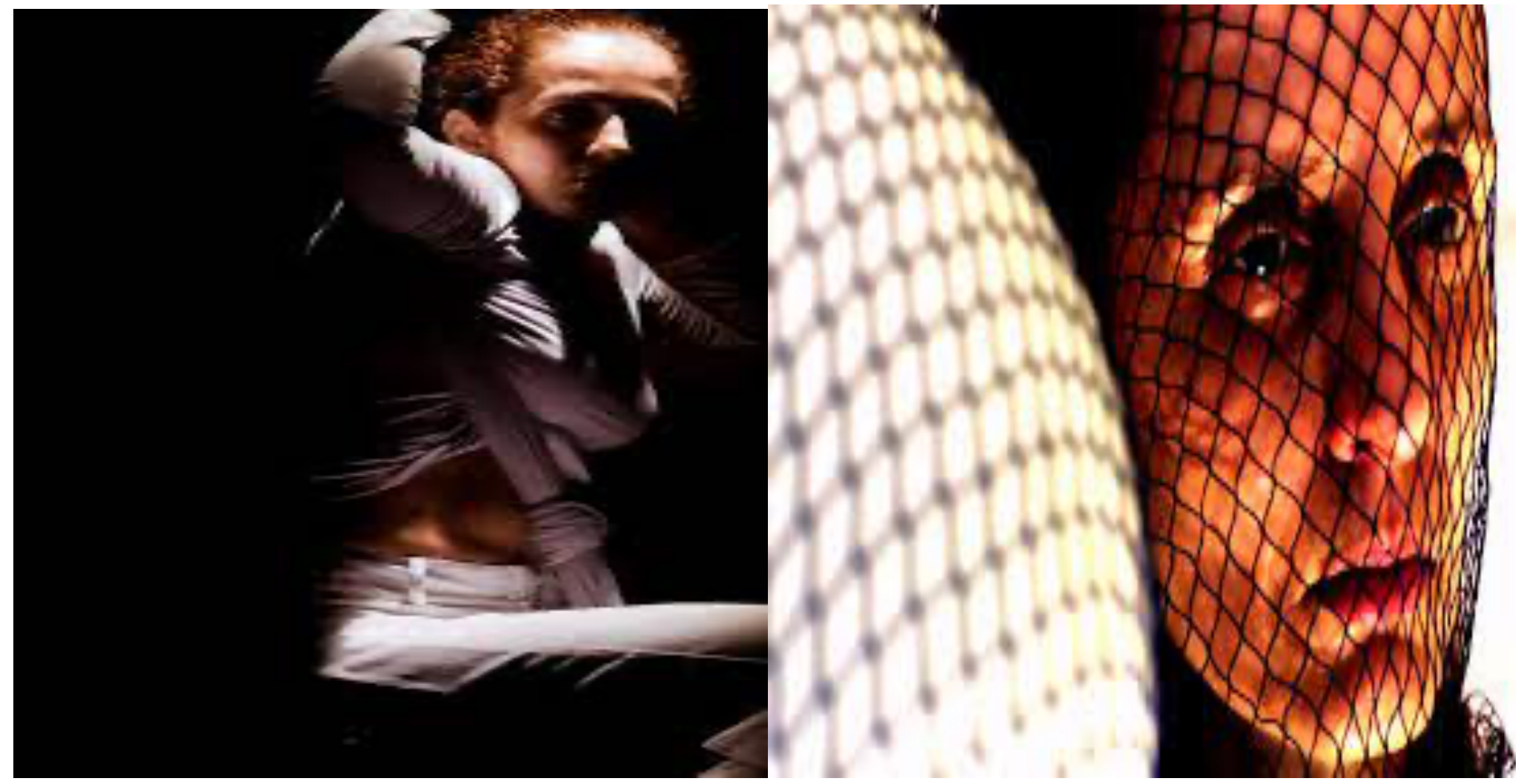

O grito saiu como tentativa de falar pelas crianças que moram e vivem naquela comunidade e não são escutadas e como tentativa de sair do automatismo de trabalhar em série ligadas a uma prática de entretenimento, mais que conhecimento. Em cena estou eu, um corpo magro, pendurado por uma corda, visivelmente abatido, com olheiras, balbuciando teorias, códigos e textos, que age e reage se reorganizando a partir do discurso da professora de Natal e das imagens apresentadas das crianças tecendo assim uma relação permeável, consequentemente fazendo inferências às memórias vivas captadas nas aulas/ensaios que se tornaram cenas dessa provocação em dança e um dos objetivos dessa proposta artística que foi apresentar as reverberações materializadas em dança. 
Segundo Helena Bastos (2008), dança é entendida com ambiente que interage, provocando e sendo provocado por questões que o corpo cria para si mesmo, ação e percepção do espaço que estão no entorno de toda esta movimentação, assim,

Sentimentos como medo, impaciência, vontade, insegurança, disciplina, raiva, autonomia, dependência, frustração, alegria, surgem na medida em que criamos. É nestes diferentes estados corporais que o corpo cria intervenções no espaço, que agora chamamos de ações. Neste ambiente complexo construímos danças. O contexto criativo é este estado geral de ações que irá produzir movimentos. Neste processo muitas vezes não sabemos se o que surge são movimentos de dança (Bastos, 2008, p.3).

Ou como sugere Fabiano Lodi (2009, p.2):

Viewpoints permite ao coordenador de uma prática corporal a diversidade de associações entre atividade física e artística, identificando socialmente princípios trabalhados nas aulas, bem como discutindo o nosso comportamento corporal nas aulas, na rua, em casa, com os amigos, entre outros.

Os exercícios de Viewpoints não tratam de fazer movimento por movimento, ou somente dançar ou ser Tiktoker, são usados também na preparação corporal de dançarinos e atores para cenas e nesse caso pude valorizar e trocar experiências com os alunos mesmo sendo bem novinhos. Mais do que agradar a direção da escola, partilhei essa atividade com os alunos e senti o prazer dos corpos vibrarem ao interagir uns com os outros. Segundo Fabiano, deve-se:

deixar claro que minha experiência com os Viewpoints na escola não foi uma receita prévia ou uma aplicação metodológica que pode ser repetida esperando ou êxito ou implicações pedagógicas tradicionais. [...], penso que sua realização plena somente é possível se houver sensibilidade, por parte do educador, de relacionar o conhecimento prévio dos estudantes ao que você propõe trabalhar (Lodi, 2009, p.4).

Assim, precisamos buscar modos de estimular cada vez mais o profissional da área ao uso consciente de variadas metodologias de ensino e sempre atentos ao caráter educativo e de formação artística do cidadão (Lodi, 2009). 
Sete tons de uma poesia: caminhos interativos de um processo em criação

De 2007 a 2013 dei aulas de dança aos alunos da Escola Municipal Artur de Sales e criei um projeto chamado SOMAR. Esse projeto acontecia no turno oposto às aulas regulares com alunos da escola e da comunidade externa, incluíamos aulas de corpo para crianças, com o objetivo de aproximá-los ao universo da dança. Observei durante esse percurso como aquelas crianças me chamavam atenção para propor algo que dialogasse com a realidade deles. E pensando nos trabalhos já desenvolvidos na escola nesse período, nas experiências e afetos compartilhados, assim como nas professoras em sala de aula, aceitei o desafio de montar uma obra de dança temática e apresentar em um teatro, algo que pudesse dar a ver o que eu e aquelas crianças sentíamos, pensávamos e sonhávamos.

Eu, juntamente com Victor Venas, com os desdobramentos colhidos durante o processo de nossa formação acadêmica foram também objetos dessa provocação artística, como por exemplo numa questão partilhada entre nós: Como inserir conceitos e trabalhos relacionados a determinados filósofos, se as crianças mal se alimentavam?

O reconhecimento de que o significado está enraizado na experiência corporal implica ainda reconhecer que tanto a capacidade imaginativa como a conceitual são dependentes dos processos sensoriomotores. Por isso o que se costuma chamar de razão não é nem uma coisa concreta nem abstrata, mas processos encarnados através dos quais nossas experiências são exploradas, criticadas e transformadas em questões (Greiner, 2010, p.90).

O projeto foi inscrito e selecionado no Edital Quarta que Dança da Fundação Cultural do Estado da Bahia - FUNCEB, em 2011 na categoria Trabalho de dança em Processo de Criação. Depois de ser apresentado fomos chamados para outras apresentações, diante da problematização que trazíamos para cena. O objetivo do projeto foi apresentar a problemática do profissional de artes em diálogo com a situação dos alunos numa escola de um dos bairros mais violentos de Salvador, o 
Alto de Santa Cruz. Contudo, no decorrer do processo surgiram mais ideias, tais como: incluir os sons locais da comunidade, a pouca escuta da família com os alunos, os diferentes estados de corpo dessas crianças no dia-dia nas aulas e suas formas de proceder no ambiente escolar, meu estado de corpo diante das tensões geradas pelos gritos das crianças e tiros que ouvíamos diariamente. Todas essas imagens reverberaram nas cenas apresentadas aliadas aos interesses estéticos do projeto, quanto a isso Cecília Salles (2006, p.22) argumenta:

Essa visão de processo de criação nos coloca em pleno campo relacional, sem vocação para o isolamento de seus componentes, exigindo, portanto, permanente atenção a contextualizações e ativação das relações que o mantém como sistema complexo.

Um dos nossos guias para montagem das cenas foram as anotações nos cadernos dos alunos. Diariamente pedia que escrevessem sobre o que sentiram após cada experiência da aula. Pude perceber que muitos falavam e escreviam que sentiam "bem", outros preferiam desenhar aleatoriamente e outros não queriam escrever. Essas anotações, desenhos e imagens também se transformaram em corpo/cena.

Pensar dança nesse contexto significa pensar corpo segundo a Teoria Corpomídia (Katz \& Greiner, 2005, p.131), assim “o corpo não é um meio por onde a informação simplesmente passa, pois toda informação que chega entra em negociação com as que já estão", sob esse olhar a dança destitui autorias dominantes, que segundo Katz \& Greiner (2005) nos leva à condução de entendimentos e coerências sem dicotomias.

\section{Considerações finais}

A ideia de processualidade como continuação e movimento, ampliam essas discussões viabilizando situações experienciadas que implicam na condição de estar vivo e se localiza na qualidade de ser/estar no mundo, ou seja, sempre se modificando diante das informações recebidas diariamente. Durante o processo dessa pesquisa, estabeleceram-se conexões em dança expandindo a abordagem 
da prática docente que desafiam e modificam continuamente convenções estabelecidas de pensar as aulas e na realização de uma obra como Sete Tons de uma poesia.

Como já citado, pensar dança sem dicotomias significa pensar nos atravessamentos diários, dentre eles, nas implicações do sistema de ensino, mesmo que o objeto temático esteja pautado na realidade dessa artista/docente e dos alunos na rede municipal de ensino. Justamente por isso, a escolha do discurso proferido pela professora de Natal como sonorização dessa pesquisa, se situa em dar continuidade a discussão implantada por ela, em relação à situação dos professores de escolas públicas. Nesse sentido, pensar o corpo que dança e descrever ações do/no corpo que é cultura, movimento, poesia, prosa, representa o sentido contaminatório resultante do caráter sistêmico em que se insere dança no seu fazer educativo, artístico, comunicacional e como produtora de novos signos.

Desde o início dessa pesquisa, algumas reflexões se abriram para outras questões do mundo, permitindo receber e alterar a todo o momento nossas informações sobre o que levaríamos para cena. Permitir ser alterado pelo contexto, espaço e tempo, ampliou nosso processo criativo, traçando inclusive um caminho perceptivo não linear sobre a proposta a ser apresentada.

Concluo que ao partilhar experiências práticas com Donnie Mather naquele primeiro encontro e logo após com os alunos em sala de aula e na escritura espaçotempo no qual a própria poética do movimento se articula ao campo sensório motor, o observar, o escutar e o dançar reverbera em um prolongamento da experiência do sentir, enquanto observador e praticante do Viewpoints. Não proponho resultados imediatos e nem grandes conquistas, porém assumo que sementes foram plantadas naquele jardim da periferia e que certamente darão frutos diferenciados, com posturas menos automatizadas, polarizadas, separatistas e agressivas, assim, mais participantes no exercício da cidadania e confiantes em si mesmas. 


\section{Referências}

BASTOS, Maria Helena Franco de Araújo. A raiz da dança é o próprio corpo. Anais: V Reunião Científica de Pesquisa e Pós-Graduação em Artes Cênicas, 2008.

BELÉM, Elisa. Judson Dance Theater: Movimentos Cotidianos para a dança. 2017. Disponível em: http://letras.cidadescriativas.org.br/2017/10/18/judson-dancetheater-movimentos-cotidianos-para-a-danca/ Acesso em: 13 ago. 21.

BOGART, Anne; LANDAU, Tina. O livro dos viewpoints: um guia prático para viewpoints e composição. São Paulo: Perspectiva, 2017.

BRITTO, Fabiana Dultra. Paisagens do corpo. In: Corpo e ambiente. Codeterminações em processo. Cadernos PPGAU/FAUFBA, Salvador: EDUFBA, v. 1, 2008.

GREINER, Christine. O Corpo em crise. Novas pistas e o curto-circuito das representações. São Paulo: Annablume, 2010.

KATZ, Helena; GREINER, Christine. Por uma teoria do corpomídia. In: GREINER, Christine. O corpo: pistas para estudos interdisciplinares. São Paulo: Annablume, 2005.

KATZ, Helena. O papel do corpo na transformação da política em biopolítica. In: GREINER, Christine. O corpo em crise: novas pistas e o circuito das representações. São Paulo: Annablume, 2010.

LODI, Fabiano. A prática viewpoints na escola: uma proposta de trabalho corporal na disciplina de Artes. Revista Gambiarra, No. 2. Ano II - 2009.

MEYER, Sandra. Viewpoints: efeitos no espaço e no tempo. 2008 Disponível em: http://www.portalabrace.org/vcongresso/textos/territorios/Sandra\%20Meyer\%20Nu nes\%20-\%20Viewpoints\%20-

\%20efeitos\%20no\%20espaco\%20e\%20no\%20tempo.pdf Acesso em: 20 ago. 21.

NÓE, Alva. Varieties of Presence. Cambridge: Harvard University Press, 2012.

RANCIÈRE, Jacques. A partilha do sensível: estética e política. São Paulo: EXO experimental org.; Ed. 34,2005.

ROLNIK, Suely. Esferas da Insurreição: Notas para uma vida não cafetinada. São Paulo: n-1 edições, 2018. 
SALLES, Cecília de Almeida. Redes de Criação - construção da obra de arte. Vinhedo. São Paulo: Horizonte, 2006.

WACHOWICZ, Fátima. O treinamento Viewpoints: uma pratica que amplia a atenção. Revista Eletrônica MAPA D2 - Mapa e Programa de Artes em Dança (e Performance) Digital. Salvador, 2016.

Recebido em: 15/08/2021

Aprovado em: 23/11/2021 